\title{
Robust Design of a Hybrid Energy System
}

\author{
Andrea Giugno ${ }^{1,}$, Luca Mantelli $^{1}$, Alessandra Cuneo $^{2}$, Alberto Traverso $^{1}$ \\ ${ }^{1}$ Thermochemical Power Group (TPG), Università degli Studi di Genova, Via Montallegro 1, 16145 \\ Genova, Italy
}

${ }^{2}$ RINA Consulting S.p.A., Via Alberto Liri 27, 16145 Genova, Italy

\begin{abstract}
Nowadays the research in energy field is focused on conversion technologies which could achieve higher efficiencies and lower environmental impact. Among these, fuel cells are considered an extremely promising technology and pressurized solid oxide fuel cell (SOFC) systems are particularly attractive for their high electric efficiency, potential for cogeneration applications, low carbon emissions and high performance at part-load. This paper aims to perform a robust design of an innovative turbocharged hybrid system model, featuring components validated with industrial data, where a turbocharger is used to pressurize the fuel cell, promising better cost effectiveness than a microturbine-based hybrid system, at small scales. This study will evaluate the impact of the main operating parameters (fuel cell area, stack current density and recuperator surface) on the plant performance, considering uncertainties in the system and creating a response surface of the model to perform the study. Finally, a study of the operating costs of such plant is performed to evaluate its profitability in the Italian market scenario.
\end{abstract}

Keywords: Robust Design, Hybrid System, Fuel Cell

\section{Introduction}

Engineering design of energy systems is performed mostly under deterministic conditions; however, it is widely demonstrated that the performance of such systems is highly affected by uncertainties related to mechanical and manufacturing parameters, limited knowledge of physics and numerical approximations introduced with models [1,2]. A single point deterministic simulation does not allow to evaluate the range of sensitivity, which may be expected from the system, and does not provide details about uncertainties, leading to an inaccurate or incomplete representation of the system considered.

The necessity of a proper evaluation of the uncertainties has driven researchers' investigations, introducing several methods along the years. However, the application of such methods (i.e. Monte $\mathrm{C}^{*}$ arlo, Polynomical Chaos, etc.) to a detailed numerical model of an energy system could require an unfeasible computational timeframe or a complicated set-up process which could easily end up in mistakes.

To perform an analysis under uncertainty of energy systems, a response surface representative of the model can be created, resulting in a polynomial which approximates the chosen responses of the model within the domain set.

\footnotetext{
*Corresponding author: andrea.giugno@edu.unige.it
} 
In this paper, a hybrid system featuring a pressurized solid oxide fuel cell (SOFC) stack and a turbocharger is studied and represented through a response surface to evaluate the influence of some design choices on net power, net efficiency and economic parameters, considering uncertainties in some of the operating parameters of the system. SOFCs are a very attractive fuel cell technology for energy conversion, as they can guarantee high electrical efficiencies, low emissions, possibility of cogeneration and modularity [3]. High temperature fuel cell exhaust gases can also be used to drive a bottoming thermodynamic cycle, raising the overall hybrid cycle efficiency to more than $70 \%$ [4], resulting in a particularly interesting application for hybrid system integration $[3,5]$.

The application of response surface methodology (RSM) to polymer electrolyte membrane fuel cell (PEMFC) has been performed by Xuan et al. [6] to evaluate its optimal operating parameters, while Boyaci et al. [7] and Kanani et al. [8] made use of the RSM to study the performance of a PEMFC. A preliminary application of the RSM to a hybrid system featuring a SOFC stack was made by Cuneo et al. [9], to evaluate the most impactful factor on the net power, steam to carbon ration and efficiency of an hybrid system, applying also a Monte Carlo on the response surface to evaluate the probability density function (PDF) of the outputs.

However, the application of the RSM to fuel cell hybrid system has not been fully exploited yet. In this paper, the application of the response surface to a SOFC hybrid system is performed, to evaluate the influence of the main operating parameters (i.e. stack current density, fuel cell and recuperator surface) on the net power and efficiency of the hybrid system, as well as on its cost, considering uncertainties in turbine and compressor efficiency and SOFC ohmic losses.

\section{Plant Layout}

The hybrid system considered for this analysis, which layout is showed in Figure 1, is composed of a SOFC stack, constituted by 1500 cells, coupled with a turbocharger in order to pressurize the fuel cell and increase its performance [10]. Adopting this solution, the power generation is lower compared to a micro gas turbine hybrid system, but it is possible to achieve a significant reduction of the plant capital cost, which is crucial to make SOFC hybrid systems commercially competitive.

In nominal conditions the plant generates a net electrical power of about $30 \mathrm{~kW}$, with an electrical current of $30.3 \mathrm{~A}$, a fuel utilization factor equal to 0.8 , a SOFC average temperature around $1071 \mathrm{~K}$ and a SOFC maximum temperature equal to $1133 \mathrm{~K}$ [11].

The air flow (blue line in Fig. 1) is pressurized by the compressor, pre-heated through the recuperator (REC) and air pre-heater (APH) and lead to the cathode side of the stack. The fuel (green line in Fig. 1), which is biogas with 50\% CH4 and 50\% CO2 molar composition, is compressed and pre-heated in the fuel pre-heater (FPH) before going into the anode ejector primary nozzle. The fuel is pre-heated by the exhausts gases (red line in Fig. 1) coming from the gas turbine recuperator. Part of the SOFC anode outlet flow is recirculated through the ejector secondary nozzle, mixed with the fuel and utilized in the reformer (REF) as a source of steam and heat for the reactions [12]. At the stack outlet the anode and cathode flows are mixed and the fuel, which has not been consumed by the SOFC, is burnt within the Off-Gas Burner (OGB), in order to provide heat to both APH and REF. At this point the flow expands into the turbine, providing the mechanical power necessary to drive the compressor, and preheats both air and fuel flows before being discharged to the ambient. It is possible to divert part of the flow from upstream to downstream of the turbine through a wastegate valve (WGV), which opening is controlled to comply with the fuel cell operational constraints (temperature gradients under $250 \mathrm{~K}$ and maximum temperature equal to $1133 \mathrm{~K}$ [13]). More details regarding this plant layout and its design parameters can be found in [11]. 


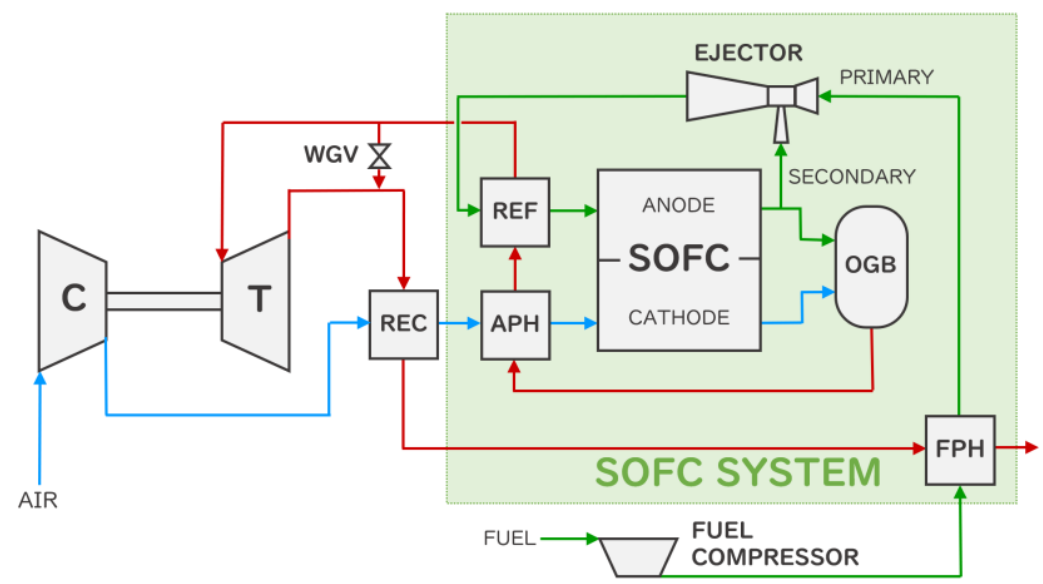

Fig. 1. Turbocharged SOFC system plant layout (blue line for the air flow, green line for the fuel, red line for the exhaust gases)

\section{Model Description}

Assembling previously developed models of its components, a steady state model of the system was created in Matlab ${ }^{\circledR}$-Simulink ${ }^{\circledR}$ to simulate its behavior with different design parameters (cell area, current density and recuperator surface), considering uncertainties of turbine and compressor efficiencies $(\eta \mathrm{t}, \eta \mathrm{c})$ and SOFC ohmic losses $\left(\mathrm{K}_{\mathrm{ohm}}\right)$.

The components models are part of a library developed within TPG and have been validated on experimental results during the past years [11]. Mass flow, pressure, temperature and composition are defined at inlet and outlet of all components and each model is based on mass and energy balance equations.

Each fuel cell in the stack is discretized in 10 finite elements and simulated as it follows: (a) the amounts of oxygen and hydrogen that react are determined from the electrical current drawn from the fuel cell stack, (b) chemical balances between reactants and products of the electrochemical reactions are computed to find the outlet compositions, (c) the temperatures of flows and cell are obtained solving energy equations which take into account heat losses to the ambient, (d) computing the Nernst's potential and subtracting mass transfer, activation and ohmic losses, the real voltage is determined. As in [11], the ohmic losses uncertainty is related to $\mathrm{K}_{\mathrm{ohm}}$, a corrective coefficient used to reduce the gap between simulation data and real behavior of the SOFC [13]. The heat exchanger model computes the outlet flow temperatures solving 1D conduction and convection equations and it is used to simulate REC, APH and FPH. It is necessary to point out that, even if APH and FPH are modelled as heat exchangers, they just represent a heat exchange between close ducts and the only component in the plant which is actually a heat exchanger is the REC. The REF is simulated with a 1D model that solves steam methane reforming and water-gas-shift reactions assuming equilibrium conditions and that computes the temperature distribution similarly to the heat exchanger model. The turbocharger model is composed by turbine and compressor 0D models, which interpolate mass flow, efficiency, rotational speed and pressure ratio maps. The rotational speed is found iteratively to ensure a turbocharger power balance equal to zero. The 0D fuel compressor model computes the fuel outlet physical properties under the assumptions of perfect gas and isentropic compression. The combustion occurring within the OGB is simulated by a 0D model based on the inlet flow chemical composition. In the OD ejector model the secondary nozzle pressure is imposed and, on the basis of the inlet flows properties, primary nozzle pressure, recirculation ratio and outlet composition are obtained. 
The system net power $\mathrm{P}_{\text {net }}$ is computed as the difference between the power generated by the SOFC $\mathrm{P}_{\mathrm{SOFC}}$ and the one consumed by the fuel compressor $\mathrm{P}_{\mathrm{c} \text {,fuel }}(1)$, while the net efficiency $\eta_{\text {net }}(2)$ is obtained as the ratio between $P_{\text {net }}$ and the fuel energy content (product between the fuel lower heating value $\mathrm{LHV}_{\text {fuel }}$ and its mas flow $\dot{\mathrm{m}}_{\text {fuel }}$ ). To better understand some of the analysis showed in this paper, it is important to underline that the fuel mass flow is determined on the basis of the fuel cell area and the electrical current density.

$$
\begin{aligned}
& P_{\text {net }}=P_{\text {SOFC }}-P_{c, \text { fuel }} \\
& \eta_{\text {net }}=\frac{P_{\text {net }}}{\dot{m}_{\text {fuel }} L H V_{\text {fuel }}}
\end{aligned}
$$

More information regarding the hybrid system model, the on-design simulation main data and results can be found in [11].

\section{Response Surface Creation}

RSM consists of a group of mathematical and statistical techniques that can be used to define the relationships between independent input variables and interested outputs. Such methodology helps to evaluate the effects of several parameters and establish the optimum conditions for the desired responses, through the creation of a mathematical model called metamodel [14]. RSM allows to correlate the $\mathrm{N}$ variables considered with a polynomial expression, which could be used to understand the response of the output of interest in respect to the variables, within the boundaries set.

In this study, to create an accurate response surface (RS) of the model, the Central Composite Design Face Centered (CCF) method is used. The effect of three parameters (factors) on the performance and economic profitability of the hybrid system within the Italian market scenario is investigated. Such factors are:

$$
\begin{aligned}
& -\quad \text { Area of a single fuel cell }\left(\mathrm{A}_{\text {cell }}\right) \\
& -\quad \text { Exchange surface of the recuperator }\left(\mathrm{S}_{\mathrm{rec}}\right) \\
& \text { - }
\end{aligned}
$$

The uncertainties related to turbine and compressor efficiencies $\left(\eta_{t}, \eta_{c}\right)$ and to the SOFC ohmic losses corrective coefficient $\left(\mathrm{K}_{\mathrm{ohm}}\right)$ were considered. The uncertain parameters were described through a Gaussian probability density function (PDF), based on industrial data and authors' knowledge [15] (Table 1 -left). For most engineering problems, a clear probability inference of parameters usually requires a large volume of experimental data, which is often impractical due to expense consideration or experimental limitations. Thus, a normal (Gaussian) distribution is popularly adopted without losing the generality, proving to be, under such circumstances, more appropriate than other distributions [9]. The coefficient of variance $(\mathrm{COV})$ is evaluated as the ratio between the standard deviation and the mean of each single variable, providing improved understanding of how the PDF is spread.

Table 1. Mean and Coefficient of Variance of the uncertain parameters (left) and factor levels considered for RS creation (right)

\begin{tabular}{|c|c|l|}
\hline Variable & $\boldsymbol{\mu}$ & $\boldsymbol{C O V}$ \\
\hline$\eta_{c}[\%]$ & $72 \%$ & $1 \%$ \\
\hline$\eta_{t}[\%]$ & $61 \%$ & $1 \%$ \\
\hline$K_{\text {ohm }}[-]$ & 0.48 & $3 \%$ \\
\hline
\end{tabular}

\begin{tabular}{|l|l|l|l|l|}
\hline Factor & \multicolumn{1}{|c|}{ Name } & $\begin{array}{c}\text { Central } \\
\text { Point }\end{array}$ & $\begin{array}{c}\text { Low } \\
\text { Level }\end{array}$ & $\begin{array}{c}\text { High } \\
\text { Level }\end{array}$ \\
\hline $\mathrm{A}$ & $\mathrm{A}_{\text {cell }}\left[\mathrm{m}^{2}\right]$ & 0.01278 & 0.01150 & 0.01406 \\
\hline $\mathrm{B}$ & $\mathrm{J}_{\text {cell }}\left[\mathrm{A} / \mathrm{cm}^{2}\right]$ & 0.237 & 0.213 & 0.261 \\
\hline $\mathrm{C}$ & $\mathrm{S}_{\mathrm{rec}}\left[\mathrm{m}^{2}\right]$ & 8.03 & 7.23 & 8.83 \\
\hline
\end{tabular}


The response surfaces were created considering a $10 \%$ variation from the central point of the factors for low and high levels, to evaluate a hybrid system which would feature a different stack but without the necessity of changing the other components due to a huge variation of the SOFC stack features (Table 1 - right).

A second-order RS metamodel was built with Design Expert ${ }^{\circledR} 11.0$ with a three-level factorial design. A total of 75 runs with the simulation model described before were done, to perform a proper $\mathrm{CCF}$, based on the following equation, performing each run 5 times $\left(\mathrm{n}^{\circ}\right.$ of repetitions) to consider the uncertainties in the system:

$$
n^{\circ} \text { of runs }=n^{\circ} \text { of repetitions }\left(2^{n^{\circ} \text { of factors }}+2 \cdot n^{\circ} \text { of factors }+1\right)
$$

The response surfaces were created for the net power and efficiency of the hybrid system and for the internal rate of return (IRR), considering an Italian market scenario and the hybrid system to operate at maximum load. The total initial investment was computed as a function of the costs of the main components of the hybrid system [16,17], while the annual cash flow considered for a 10-year life span of the system was computed as:

$$
C F N_{j}=C_{e l} \cdot P_{N E T}-C_{f} \cdot P_{f}-C_{\text {maint }}
$$

where the annual maintenance cost was calculated as the sum of $10 \%$ of the SOFC initial investment and $3 \%$ of the other components initial investment: this allows to take into consideration the substitution of the stack after 5 years, amortized along the time span set as end-of-life (EOL) of the plant. The main economic parameters used for this analysis are illustrated in the following table (Table 2). The electrical price is favourable because of potential on-site self-consumption of the produced energy or renewable feed-in-tariff scenario.

Table 2. Economic parameters used for the analysis

\begin{tabular}{|l|l|}
\hline Revenue & $C_{e l}=0.15 € / \mathrm{kWh}$ \\
\hline Operational Cost & $\begin{array}{l}C_{f}=0.27 € / \mathrm{kg} \\
C_{\text {maint }}=10 \% \text { of } S O F C+3 \% \text { of other components }\end{array}$ \\
\hline Operating hours & $\begin{array}{l}E O H=8000 \mathrm{~h} / \mathrm{yr} \\
E O L=10 \mathrm{yrs} .\end{array}$ \\
\hline
\end{tabular}

\section{Results}

To identify the most suitable model (i.e. quadratic, linear, cubic) for the creation of the response surfaces of net power, efficiency and IRR, an ANOVA was performed and used to evaluate which single factor and combination of them were significant. The ANOVA suggested that a quadratic model was significant for representing the net power, resulting in a predicted $\mathrm{R}^{2}$ of 0.9891 (i.e. maximum $\mathrm{R}^{2}$ value would be 1 in case of perfect fitting of the RS with the model), which represents the degree to which the input variables explain the variation of the output/predicted variable, in good agreement with the adjusted $\mathrm{R}^{2}$ of 0.9899 , which gives the percentage of variation explained by only those independent variables that in reality affect the dependent variable. ANOVA suggested instead that a linear model would have been good enough to represent net efficiency and IRR.

In

Table 3 the $\mathrm{R}^{2}$ values of the three response surfaces are reported, as well as the deterministic nominal values of net power, net efficiency, IRR and their minimum and maximum values produced from the 75 runs performed under uncertainty, to build the RS. 
Table 3. RS results

\begin{tabular}{|c|c|c|c|c|c|}
\hline Response variable & Predicted R $^{\mathbf{2}}$ & Adjusted R $^{\mathbf{2}}$ & Nom. value & Min. Value & Max. Value \\
\hline$P_{\text {net }}[\mathrm{kW}]$ & 0.9891 & 0.9899 & 30.56 & 25.18 & 36.21 \\
\hline$\eta_{\text {net }}[-]$ & 0.8639 & 0.8716 & 51.75 & 48.97 & 53.79 \\
\hline IRR [-] & 0.5530 & 0.5790 & 0.1736 & 0.1444 & 0.1963 \\
\hline
\end{tabular}

It can be observed that the IRR presents a low $\mathrm{R}^{2}$, suggesting that the model is not very representative of the real behaviour of this variable within the boundaries considered, related also to the strong impact of uncertainties on it. This result can be also highlighted from the RS representation presented in Fig. 2(b), as the simulation points highlighted with red dots are more scattered than for the net efficiency RS. Instead, the $\mathrm{R}^{2}$ of net power and net efficiency is good and the RS obtained is then well representative of the plant performance.

The factors which have the strongest impact on net power, are cell area and current density, as it is directly related to them. The net efficiency is mainly influenced by current density and its increase for lower values of $\mathrm{J}_{\text {cell }}$ is due to the SOFC ohmic losses reduction.

Net efficiency behaviour is however slightly different than net power one, as it can be also observed from the $\mathrm{R}^{2}$ value, as the efficiency also depends on the fuel mass flow (eq. 2) which is computed from the model as a function of current density and cell area.

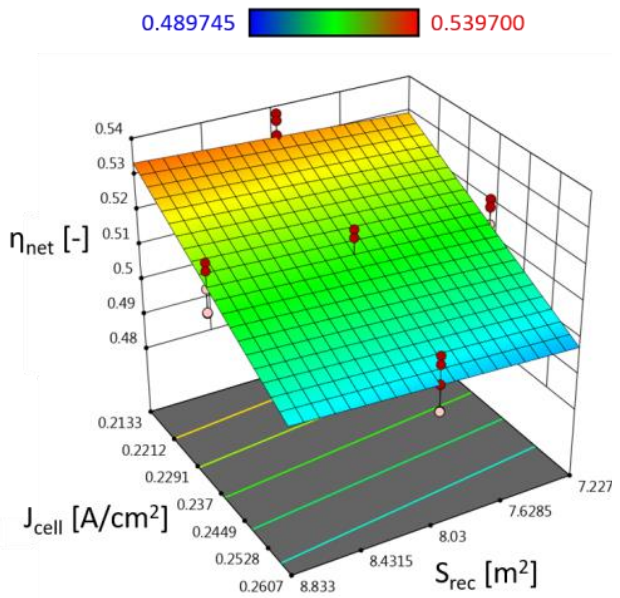

(a)

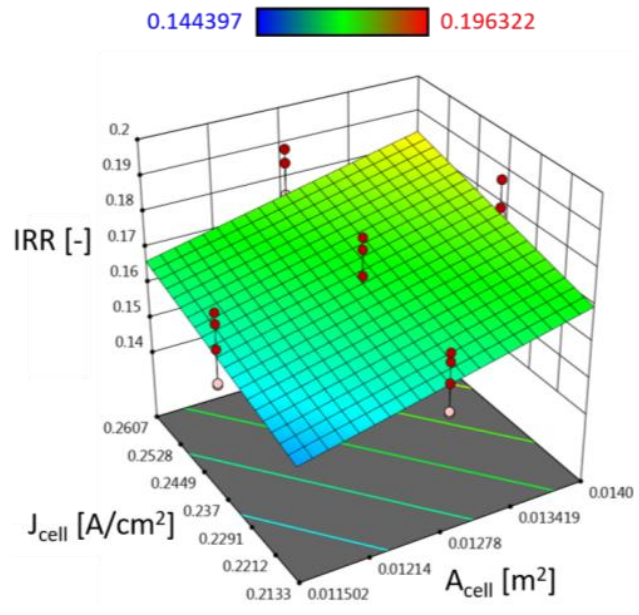

(b)

Fig. 2. Response surfaces of (a) net efficiency as a function of $J_{\text {cell }}$ and $S_{\text {rec }}\left(A_{\text {cell }}=0.01278 \mathrm{~m}^{2}\right)$ and (b) IRR as a function of $\mathrm{J}_{\text {cell }}$ and $\mathrm{A}_{\text {cell }}\left(\mathrm{S}_{\mathrm{rec}}=8.03 \mathrm{~m}^{2}\right)$.

The factors which have the strongest impact on IRR are the current density and the cell area, as they both impact directly the net power and so the revenues, despite a higher cost of the SOFC stack, while the recuperator surface has a particularly low impact on the IRR. Within the scenario considered in this paper, it appears to be more important to sell as much energy as possible to increase the profitability of the plant. In a scenario with higher natural gas price and lower electricity value, the conclusions could differ. 


\section{Conclusions}

In this work a response surface of a SOFC turbocharged hybrid system has been created to evaluate the impact of some of the main operating parameters (cell area, current density and recuperator surface) on its performance and economic profitability, considering uncertainties related to turbine and compressor efficiency and to SOFC ohmic losses.

Results show that the uncertainties have a strong impact on the evaluation of the IRR, suggesting that proper uncertainty quantification should be performed when the economic analysis of such systems is targeted. On the other hand, their impact on the net efficiency is lower, even if still important, while the effect on net power can be considered almost negligible. The ANOVA and the response surfaces highlighted that the current density is the most important factor for the evaluation of net power, net efficiency and IRR, as it drives directly the net power produced and so the revenues.

This study represents the starting point for a deeper evaluation of the full operational envelope of the hybrid system considered, and the response surfaces are currently being used to perform a multi-objective optimization of the system, subject to uncertainty, to evaluate the best solution which would take into consideration both performance and economic profitability.

This project has received funding from the European Union's Horizon 2020 research and innovation programme under grant agreement No 641073, Bio-HyPP project (http://www.bio-hypp.eu).

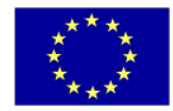

\section{References}

[1] Cuneo, A., Traverso, A., and Shahpar, S., 2017, "Comparative Analysis of Methodologies for Uncertainty Propagation and Quantification," Proceedings of the ASME Turbo Expo, p. V02CT47A005.

[2] Ghanem, R., Owhadi, H., and Higdon, D., 2017, Handbook of Uncertainty Quantification.

[3] Zhang, X., Chan, S. H., Li, G., Ho, H. K., Li, J., and Feng, Z., 2010, “A Review of Integration Strategies for Solid Oxide Fuel Cells,” J. Power Sources, 195(3), pp. 685-702.

[4] Damo, U.M., Ferrari, M.L., Turan, A., Massardo, A. F., 2015, “Test Rig for Hybrid System Emulation: New Real-Time Transient Model Validated in a Wide Operative Range," Fuel Cells, 15, pp. 7-14.

[5] Cuneo, A., Zaccaria, V., Tucker, D., and Sorce, A., 2018, “Gas Turbine Size Optimization in a Hybrid System Considering SOFC Degradation,” Appl. Energy.

[6] Xuan, D., Li, Z., Kim, J., and Kim, Y., 2009, "Optimal Operating Points of PEM Fuel Cell Model with RSM,” J. Mech. Sci. Technol.

[7] Boyaci San, F. G., Isik-Gulsac, I., and Okur, O., 2013, "Analysis of the Polymer Composite Bipolar Plate Properties on the Performance of PEMFC (Polymer Electrolyte Membrane Fuel Cells) by RSM (Response Surface Methodology), Energy.

[8] Kanani, H., Shams, M., Hasheminasab, M., and Bozorgnezhad, A., 2015, "Model Development and Optimization of Operating Conditions to Maximize PEMFC Performance by Response Surface Methodology,” Energy Convers. Manag.

[9] Giugno, A., Cuneo, A., and Traverso, A., 2019, "Analysis of Uncertainties in Compact Plate-Fin Recuperators for Microturbines," Appl. Therm. Eng., 150(September 2018), pp. 1243-1251. 
[10] Henke, M., Kallo, J., Friedrich, K. A., and Bessler, W. G., 2011, "Influence of Pressurisation on SOFC Performance and Durability: A Theoretical Study," Fuel Cells, pp. 581-591.

[11] Cuneo, A., Mantelli, L., Giugno, A., and Traverso, A., 2019, “Uncertainty Quantification Analysis of a Pressurised Fuel Cell Hybrid System," Proceedings of ASME Turbo Expo 2019: Turbomachinery Technical Conference and Exposition, Phoenix, pp. 1-15.

[12] Venkataraman, K., Wanat, E. C., and Schmidt, L. D., 2003, "Steam Reforming of Methane and Water-Gas Shift in Catalytic Wall Reactors," AIChE J., 49(5), pp. 1277-1284.

[13] STAXERA, SOFC Stack - Mk200, Product Data Sheet.

[14] Gunst, R. F., Myers, R. H., and Montgomery, D. C., 2006, "Response Surface Methodology: Process and Product Optimization Using Designed Experiments," Technometrics.

[15] Cuneo, A., Zaccaria, V., Tucker, D., and Traverso, A., 2017, "Probabilistic Analysis of a Fuel Cell Degradation Model for Solid Oxide Fuel Cell and Gas Turbine Hybrid Systems," Energy, 141, pp. 2277-2287.

[16] Arsalis, A., 2008, "Thermoeconomic Modeling and Parametric Study of Hybrid SOFC-Gas Turbine-Steam Turbine Power Plants Ranging from 1.5 to $10 \mathrm{MWe,"J.}$ Power Sources, 181(2), pp. 313-326.

[17] Galanti, L., and Massardo, A. F., 2011, "Micro Gas Turbine Thermodynamic and Economic Analysis up to 500 KWe Size,” Appl. Energy, 88(12), pp. 4795-4802. 